\title{
Article
}

\section{Reversible carbon dioxide capture at high temperatures by tetraethylenepentamine acetic acid and polyethylene glycol mixtures with high capacity and low viscosity}

Bin Zhang, Anna Bogush, Jiangxiong Wei, Tongsheng Zhang, Jie Hu, Fangxian Li, and Qijun Yu Energy Fuels, Just Accepted Manuscript • DOI: 10.1021/acs.energyfuels.6b03458 • Publication Date (Web): 10 Mar 2017

Downloaded from http://pubs.acs.org on March 21, 2017

\section{Just Accepted}

"Just Accepted" manuscripts have been peer-reviewed and accepted for publication. They are posted online prior to technical editing, formatting for publication and author proofing. The American Chemical Society provides "Just Accepted" as a free service to the research community to expedite the dissemination of scientific material as soon as possible after acceptance. "Just Accepted" manuscripts appear in full in PDF format accompanied by an HTML abstract. "Just Accepted" manuscripts have been fully peer reviewed, but should not be considered the official version of record. They are accessible to all readers and citable by the Digital Object Identifier (DOI®). "Just Accepted" is an optional service offered to authors. Therefore, the "Just Accepted" Web site may not include all articles that will be published in the journal. After a manuscript is technically edited and formatted, it will be removed from the "Just Accepted" Web site and published as an ASAP article. Note that technical editing may introduce minor changes to the manuscript text and/or graphics which could affect content, and all legal disclaimers and ethical guidelines that apply to the journal pertain. ACS cannot be held responsible for errors or consequences arising from the use of information contained in these "Just Accepted" manuscripts. 


\title{
Reversible carbon dioxide capture at high temperatures by
}

tetraethylenepentamine acetic acid and polyethylene glycol mixtures with high capacity and low viscosity

\author{
Bin Zhang ${ }^{1}$, Anna Bogush ${ }^{2}$, Jiangxiong Wei ${ }^{1,3 *}$, Tongsheng Zhang ${ }^{1}$, Jie Hu ${ }^{1}$, Fangxian $\mathrm{Li}^{1}$, Qijun $\mathrm{Yu}^{1,3}$ \\ 1. School of Materials Science and Engineering, South China University of Technology, \\ Guangzhou 510640, Guangdong, China \\ 2. Centre for Resource Efficiency \& the Environment (CREE), Department of Civil, \\ Environmental \& Geomatic Engineering (CEGE), University College London (UCL), \\ Chadwick Building, Gower Street, London WC1E 6BT, UK \\ 3. Guangdong Low Carbon Technologies Engineering Center for Building Materials, \\ Guangzhou 510640, Guangdong, China
}

\begin{abstract}
Ionic liquids (ILs) are investigated in many studies to capture $\mathrm{CO}_{2}$ in recent years. However, almost all of these studies carried out the absorption of $\mathrm{CO}_{2}$ by ILs at relatively low temperatures (lower than $333.15 \mathrm{~K}$ or even around the room temperature). Besides, the viscosity of ILs increases dramatically after absorbing $\mathrm{CO}_{2}$ which could reduce the absorption efficiency significantly. Reversible and efficient absorption of $\mathrm{CO}_{2}$ at high temperatures was investigated by IL of tetraethylenepentamine acetic acid ([TEPA]Ac) and polyethylene glycol 200 (PEG-200) mixtures with low viscosity. The results showed that the absorption capacity
\end{abstract}

\footnotetext{
*Corresponding author: jxwei@scut.edu.cn, Tel.: +86020 87114137
} 
of [TEPA]Ac/PEG-200 mixtures achieved to $1.24 \mathrm{~mol} \mathrm{CO}_{2}$ per mole [TEPA]Ac at $353.15 \mathrm{~K}$ at ambient pressure (1.01 bar). The mixtures could be easily regenerated by bubbling dried $\mathrm{N}_{2}$ through them. The addition of PEG-200 in the [TEPA]Ac could increase the efficiency of absorption and desorption significantly. Furthermore, the solubility data of $\mathrm{CO}_{2}$ in the [TEPA]Ac/PEG-200 mixtures at $\mathrm{T}=(353.15,368.15,383.15$, and 398.15) $\mathrm{K}$ under different pressures were measured and the solution enthalpy $\left(\Delta \mathrm{H}_{\mathrm{sol}}\right)$ and solution entropy $\left(\Delta \mathrm{S}_{\mathrm{sol}}\right)$ were calculated. Under all the conditions, the negative value of $\Delta \mathrm{H}_{\mathrm{sol}}$ indicated that the capture process is exothermic. The process of $\mathrm{CO}_{2}$ capture described that using [TEPA]Ac/PEG-200 mixtures is a promising approach for $\mathrm{CO}_{2}$ absorption with high reversibility and excellent absorption property at a relatively high temperature.

Keywords: Carbon capture, Ionic liquid, Tetraethylenepentamine acetic acid, Polyethylene glycol, High temperature, High capacity

\section{Introduction}

The emission of $\mathrm{CO}_{2}$ from fossil fuel combustion causes serious effect to the environment and contributes to global warming and ocean acidification. Therefore, the concept of carbon capture and storage (CCS) has drawn considerable attention by the researchers during these years $[1,2]$. The carbon capture technologies such as absorption, adsorption, and membrane gas separation technologies are developed and applied worldwide [3-8]. Physical absorbents, such as monoethanolamine (MEA), can absorb $\mathrm{CO}_{2}$ at high partial pressures and low temperatures, which have been used industrially for many years. However, 
large energy consumption was consumed and partial decomposition occurred during regeneration process. Adsorption materials, such as carbon-based sorbents (e.g. carbon molecular sieves) and metal oxides (e.g. $\mathrm{CaO}, \mathrm{Li}_{2} \mathrm{ZrO}_{3}$ ) have been used for $\mathrm{CO}_{2}$ capture at high temperature (above $300 \square$ ). For example, the $\mathrm{CaO}$ can capture $\mathrm{CO}_{2}$ at $600-800 \square$ with the mole ratio approach of 1.0 and regenerated at $800-850 \square$. In addition, membrane is also a type of promising utilization of reversible material for $\mathrm{CO}_{2}$ capture. The advantages of membrane absorption material are selective extraction of $\mathrm{CO}_{2}$ from mixed gas streams and flexibility in their possible configurations in industrial plants. However, a common disadvantage of the membrane materials is their lack of stability under the application environment [7-10]. Therefore, seeking promising alternatives with low energy consumption and high stability to these solvents is desirable.

Ionic liquid (IL) is a promising material regarded as a kind of environmentally-friendly solvent which processes some superior properties, for example, wide liquid temperature range, low vapor pressure, high thermal and chemical stability, and excellent solvent power [11, 12]. Recently, there is a significant progress in the application of IL for $\mathrm{CO}_{2}$ capturing. Blanchard et al. [13] firstly reported that $\mathrm{CO}_{2}$ could be absorbed by 1-butyl-3-methylimidazolium hexafluorophosphate $[\mathrm{BMIM}]\left[\mathrm{PF}_{6}\right]$ effectively, but the IL of [BMIM] $\left[\mathrm{PF}_{6}\right]$ could not be dissolved in $\mathrm{CO}_{2}$. After that, many researchers were engaged in the study of $\mathrm{CO}_{2}$ capturing with ionic liquid $[14,15]$. Bates et al. [16] synthesized a kind of IL by inducing a primary amine moiety and tetrafluoroborate anion to the structure of imidazolium cation and studied its property related to $\mathrm{CO}_{2}$ absorption. Their results showed that the IL had a good effect on carbon absorption and molar absorption ratio of $\mathrm{CO}_{2}$ to IL 
could approach 0.5. Galan Sanchez et al. [17] studied the absorption of $\mathrm{CO}_{2}$ in different imidazolium-based ILs. They found out that the efficiency of $\mathrm{CO}_{2}$ absorption increased significantly by attaching basic groups to the structure of the ILs. Gurkan et al. [18] reported that equimolar amount of $\mathrm{CO}_{2}$ could be absorbed by the IL with amino acids anion. Zhang et al. [19] synthesized the phosphonium-based ILs with various amino acid anions for carbon capture. When the ILs were saturated with $\mathrm{CO}_{2}$, the mole ratio of $\mathrm{CO}_{2}$ to IL approached to 1.0 .

Although ILs have many attractive superiorities for $\mathrm{CO}_{2}$ capturing, they still have some drawbacks that need to be modified, such as promoting the absorption capacity and decreasing the viscosity $[20,21]$. Furthermore, the capacity of $\mathrm{CO}_{2}$ absorption by the present ILs declined dramatically when temperature elevated to $353.15 \mathrm{~K}$ [22]. Thus, their application for the $\mathrm{CO}_{2}$ capture and storage was limited at low temperatures, being less than $333.15 \mathrm{~K}$ or even at room temperature $[23,24]$. However, temperature of the flue gas is usually higher than room temperature and ranges from $353.15 \mathrm{~K}$ to $393.15 \mathrm{~K}$. Therefore, designing new absorbents to capture $\mathrm{CO}_{2}$ at higher temperatures (from $353.15 \mathrm{~K}$ to $393.15 \mathrm{~K}$ ), with high absorption capacity, and high efficiency is required.

In the present work, a new type of IL-based adsorbent of tetraethylenepentamine acid ([TEPA]Ac) and [TEPA]Ac in polyethylene glycol (PEG) with average molecular weight of $200 \mathrm{~g} / \mathrm{mol}$ (PEG-200) was studied for carbon capture. PEG-200 was mainly selected as a solvent to dissolve [TEPA]Ac in order to decrease the viscosity of the IL after absorbing $\mathrm{CO}_{2}$. Also, PEG has other important advantages, such as nontoxic, biodegradable, nonvolatile, and cheap $[25,26]$. In addition, the solubility of $\mathrm{CO}_{2}$ in [TEPA]Ac/PEG-200 mixture at four 
temperatures under different pressures was also measured and the thermodynamic parameters were calculated by the thermodynamics theory and solubility data.

\section{Materials and methods}

2.1 Materials

$\mathrm{CO}_{2}(99.999 \%)$ and $\mathrm{N}_{2}(99.999 \%)$ were provided from Messer Gases Co. Ltd. (Guangzhou, China). Tetraethylenepentamine (TEPA) ( $\geq 99 \%$ ) was supplied by Damao chemical reagent Co. Ltd. (Tianjin, China). Acetic acid (Ac) $(\geq 99.5 \%)$ and polyethylene glycol (PEG-200, $\geq 99.5 \%$ ) were purchased from Runjie chemical reagent Co. Ltd. (Tianjin, China).

2.2 Synthesis of [TEPA]Ac and the preparation of [TEPA]Ac/PEG-200 mixtures.

[TEPA]Ac was synthesized in following reaction:

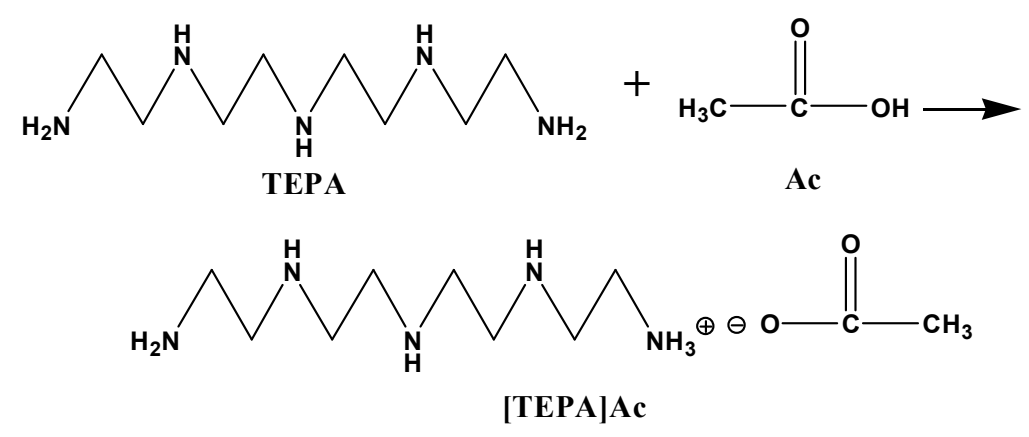

The procedure included following steps: 1) $0.5 \mathrm{~mol}$ of TEPA and $150 \mathrm{~mL}$ of water were added into a $500 \mathrm{~mL}$ three-necked flask which was placed in an ice-water bath with a magnetic stirrer; 2) $0.5 \mathrm{~mol}$ of Ac was added dropwise from a pressure funnel to the flask over about $1.0 \mathrm{~h}$. Then the reaction continued for $8 \mathrm{~h}$ at $298.15 \mathrm{~K} .3$ ) After that, the water was removed by a rotary evaporator and being dried under vacuum at $353.15 \mathrm{~K}$ for more than $48 \mathrm{~h}$ 
before use. After the drying process, the fractions of water were less than $0.5 \%$ which were determined by Karl Fischer titration.

The mixtures of [TEPA]Ac/PEG-200 were prepared with mass ratio of [TEPA]Ac to PEG-200 at 1:1, 1:2 and 1:3 by an analytical balance (AR224CN, OHAUS) with a precision of $0.1 \mathrm{mg}$. After mixing, the solutions were kept in the vacuum oven at $353.15 \mathrm{~K}$ for 48 hours to remove the volatile impurities and possible traces of water and then stored in a desiccator.

\subsection{Absorption and desorption of $\mathrm{CO}_{2}$}

The process of absorption and desorption of $\mathrm{CO}_{2}$ was carried out at ambient pressure. Figure 1 shows an experimental device for absorption and desorption of $\mathrm{CO}_{2}$ by [TEPA]Ac. The temperature of an oil bath was controlled by a thermo controller. About $5.0 \mathrm{~g}$ of the [TEPA]Ac/PEG-200 mixture was loaded in the glass tube which was partly immersed in the oil bath at desired temperature, and then $\mathrm{CO}_{2}$ was bubbled through the absorbent at the rate of $100 \mathrm{~cm}^{3} /$ min which was controlled by the gas rotameter.

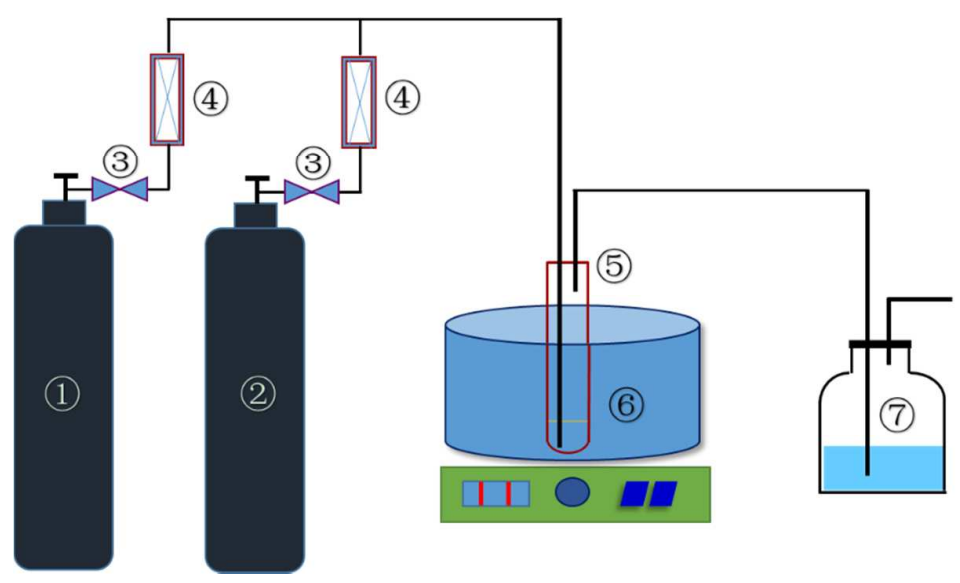

Fig. 1 Experimental device for $\mathrm{CO}_{2}$ absorption and desorption by [TEPA]Ac: (1) Cylinder 
filled with pure $\mathrm{N}_{2}$; (2) Cylinder filled with pure $\mathrm{CO}_{2}$; (3) Valves; (4) Flow meters; (5) Glass tube filled with [TEPA]Ac or [TEPA]Ac/PEG-200; 6) Oil baths; (7) NaOH aqueous solution for absorbing the exhaust $\mathrm{CO}_{2}$.

The total weight of the glass tube including adsorbent and the needle was measured at regular intervals by an analytical balance (AR224CN, OHAUS). Then the absorbed $\mathrm{CO}_{2}$ could be calculated through the weight increase of the glass tube. After that, dried $\mathrm{N}_{2}$ was bubbled through the solution to regenerate the absorbent. The absorption of pure $\mathrm{N}_{2}$ in [TEPA]Ac and [TEPA]Ac/PEG-200 mixtures at 353.15 $\mathrm{K}$ was also measured. The results showed that the content of $\mathrm{N}_{2}$ absorbed by the [TEPA]Ac was less than $0.1 \%$, which could be neglected during this study.

The viscosity of [TEPA]Ac/PEG-200 during the absorption of $\mathrm{CO}_{2}$ was measured by a shear rate-controlled rheometer (Brookfield R/S plus) equipped with a shear vane (four blades with $20 \mathrm{~mm}$ in width and $40 \mathrm{~mm}$ in length).

\subsection{Solubility of $\mathrm{CO}_{2}$ in [TEPA]Ac/PEG-200 mixtures}

$\mathrm{CO}_{2}$ solubility measurement was performed on the basis of the isochoric saturation method [27]. Figure 2 shows the apparatus to measure $\mathrm{CO}_{2}$ solubility. This device mainly consists of a $\mathrm{CO}_{2}$ gas equilibrium cell $\left(50 \mathrm{~cm}^{3}\right)$ with a magnetic stirrer, a gas reservoir (1000 $\mathrm{cm}^{3}$ ), an oil bath and a pressure gauge (0-1.0 bar) with an accuracy of 0.0005 bar. The temperature of the oil bath was controlled by the thermo controller. 


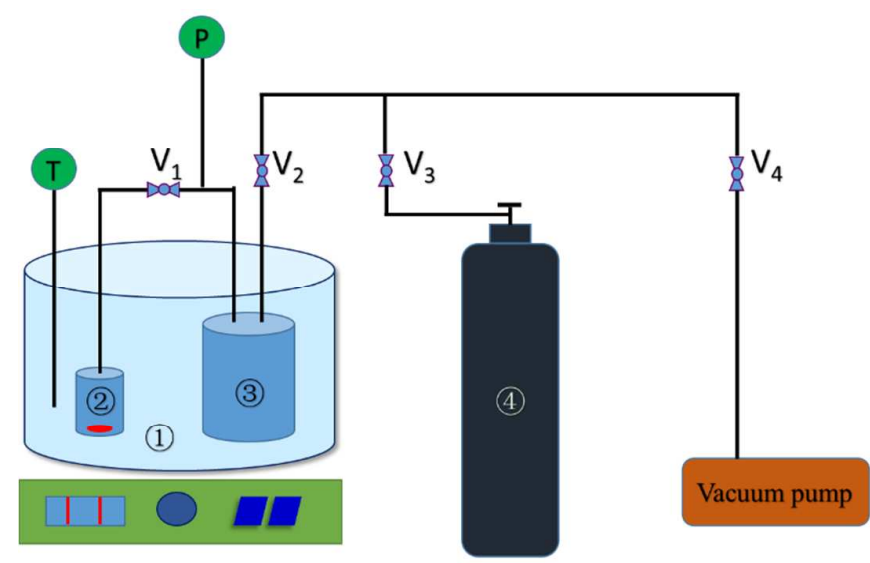

Fig. 2 Experimental device for measurement of $\mathrm{CO}_{2}$ solubility. (1) Oil bath; (2) $\mathrm{CO}_{2}$ gas equilibrium cell; (3) $\mathrm{CO}_{2}$ gas reservoir; (4) Cylinder filled with pure $\mathrm{CO}_{2} ; \mathrm{V} 1-\mathrm{V} 4$, Valves; (P) Pressure transmitter; (T) Thermo controller.

In a typical experiment, about $5 \mathrm{~g}$ of [TEPA]Ac/PEG-200 was loaded into the equilibrium cell and degassed at $298.15 \mathrm{~K}$ under vacuum for at least $1 \mathrm{~h}$. The mass of the absorbent was determined by the electronic balance. At a fixed oil-bath temperature, the valve of $V_{3}$ was closed, $\mathrm{V}_{1}, \mathrm{~V}_{2}$ and $\mathrm{V}_{4}$ were opened and the whole system was evacuated to pressure $\mathrm{p}_{1}$. Then $\mathrm{V}_{1}$ and $\mathrm{V}_{4}$ were closed and $\mathrm{V}_{3}$ was opened. The gas reservoir was loaded with $\mathrm{CO}_{2}$ from the gas cylinder until the pressure reached a scheduled value $\left(\mathrm{P}_{2}\right)$, which was closed to atmospheric pressure. After that, $\mathrm{V}_{2}$ and $\mathrm{V}_{3}$ were closed and $\mathrm{V}_{1}$ was opened. Then $\mathrm{CO}_{2}$ was charged into the equilibrium cell and began being dissolved by [TEPA]Ac/PEG-200 while stirring. It was assumed that equilibrium was reached after the pressure of the system had been constant for $3 \mathrm{~h}$. The final pressure was recorded as $\mathrm{p}_{3}$. The equilibrium partial pressure of $\mathrm{CO}_{2}$ was obtained as $\left(\mathrm{p}_{3}-\mathrm{p}_{1}\right)$. Then $\mathrm{V}_{1}$ was closed and the mass of cell was determined. The total $\mathrm{CO}_{2}$ amount in the equilibrium cell was easily obtained by the masses of cell with and 
without the charge of $\mathrm{CO}_{2}$. Since the experiment was conducted at sub-atmospheric pressure and above the room temperature, the mass of gaseous $\mathrm{CO}_{2}$ in the equilibrium cell could be calculated based on the ideal gas law. Therefore, the content of $\mathrm{CO}_{2}$ in the absorbent could be calculated by deducting the mass of gaseous $\mathrm{CO}_{2}$ from the total $\mathrm{CO}_{2}$ amount.

In this work, the solubility of $\mathrm{CO}_{2}$ in the [TEPA]Ac/PEG-200 mixtures with the mass ratio of [TEPA]Ac to PEG-200 at 1:1, 1:2 and 1:3 were measured at four temperatures (353.15 K, $368.15 \mathrm{~K}, 383.15 \mathrm{~K}$, and $395.15 \mathrm{~K})$. The amount of $\mathrm{CO}_{2}$ absorbed in the absorbent can be calculated by the following equation,

$\mathrm{n}_{\mathrm{CO}_{2}}=\left(\mathrm{m}_{2}-\mathrm{m}_{1}\right) / 44-\left(\mathrm{P}_{3}-\mathrm{P}_{1}\right)\left(\mathrm{V}_{\text {cell }}-\mathrm{V}_{\text {mixture }}\right) / \mathrm{RT}$

where $\mathrm{V}_{\text {cell }}$ is the volume of gas equilibrium cell; $\mathrm{V}_{\text {mixture }}$ represents the volume of the [TEPA]Ac/PEG-200 mixture. The $\mathrm{m}_{2}$ and $\mathrm{m}_{1}$ are the mass of the cell containing [TEPA]Ac/PEG-200 before and after loading $\mathrm{CO}_{2}$ into the cell, respectively. Besides, 44 is the molecular mass of $\mathrm{CO}_{2}$.

The volume of [TEPA]Ac/PEG-200 mixtures increased about $3 \%$ after statured with $\mathrm{CO}_{2}$. Therefore, the effect of expansion of [TEPA]Ac/PEG-200 mixtures on solubility calculation of $\mathrm{CO}_{2}$ can be neglected.

\section{Results and discussion}

\subsection{Absorption and desorption of $\mathrm{CO}_{2}$}

Based on the mechanism for the ILs with amine to capture $\mathrm{CO}_{2}$ reported in some literatures $[19,28]$, it can be proposed that the process of $\mathrm{CO}_{2}$ absorption and desorption in [TEPA]Ac should follow the mechanism as shown in Scheme 1. 

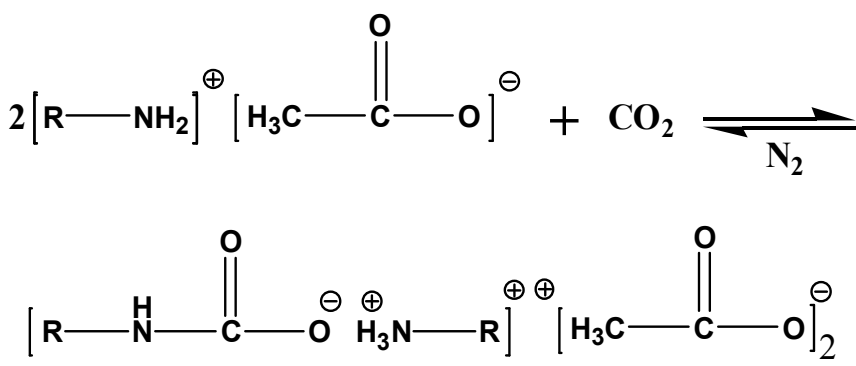

Scheme 1 Mechanism on absorption and desorption of $\mathrm{CO}_{2}$ by [TEPA]Ac

Figure 3 shows the results from experiments on absorption and desorption of $\mathrm{CO}_{2}$ in/from [TEPA]Ac/PEG-200 mixtures with the mass ratio of 1:0, 1:1, 1:2, and 1:3. For the [TEPA]Ac/PEG-200 mixtures, the experiments were conducted at $\mathrm{T}=353.15 \mathrm{~K}$ with $\mathrm{CO}_{2}$ and $\mathrm{N}_{2}$ of ambient pressure. For the pure [TEPA]Ac, the experiments were carried out at $383.15 \mathrm{~K}$ because the viscosity of [TEPA]Ac became very high $(1550 \mathrm{mPa} \cdot \mathrm{s}$, Table 1$)$ after absorbing $\mathrm{CO}_{2}$ at $\mathrm{T}=353.15 \mathrm{~K}$. The content of PEG-200 has a strong effect on the $\mathrm{CO}_{2}$ absorption rate (Fig. 3). The equilibrium absorption time was around $160 \mathrm{~min}$ for pure [TEPA]Ac. With the content of PEG-200 increased, the $\mathrm{CO}_{2}$ absorption rate of [TEPA]Ac/PEG-200 mixtures increased dramatically even at a lower temperature (Figure 3). For example, the time required for $\mathrm{CO}_{2}$ absorption up to saturation is about $85 \mathrm{~min}, 39 \mathrm{~min}$, and $27 \mathrm{~min}$ at $353.15 \mathrm{~K}$ when the mass ratio of [TEPA]Ac to PEG-200 equals 1:1, 1:2, and 1:3, respectively. 

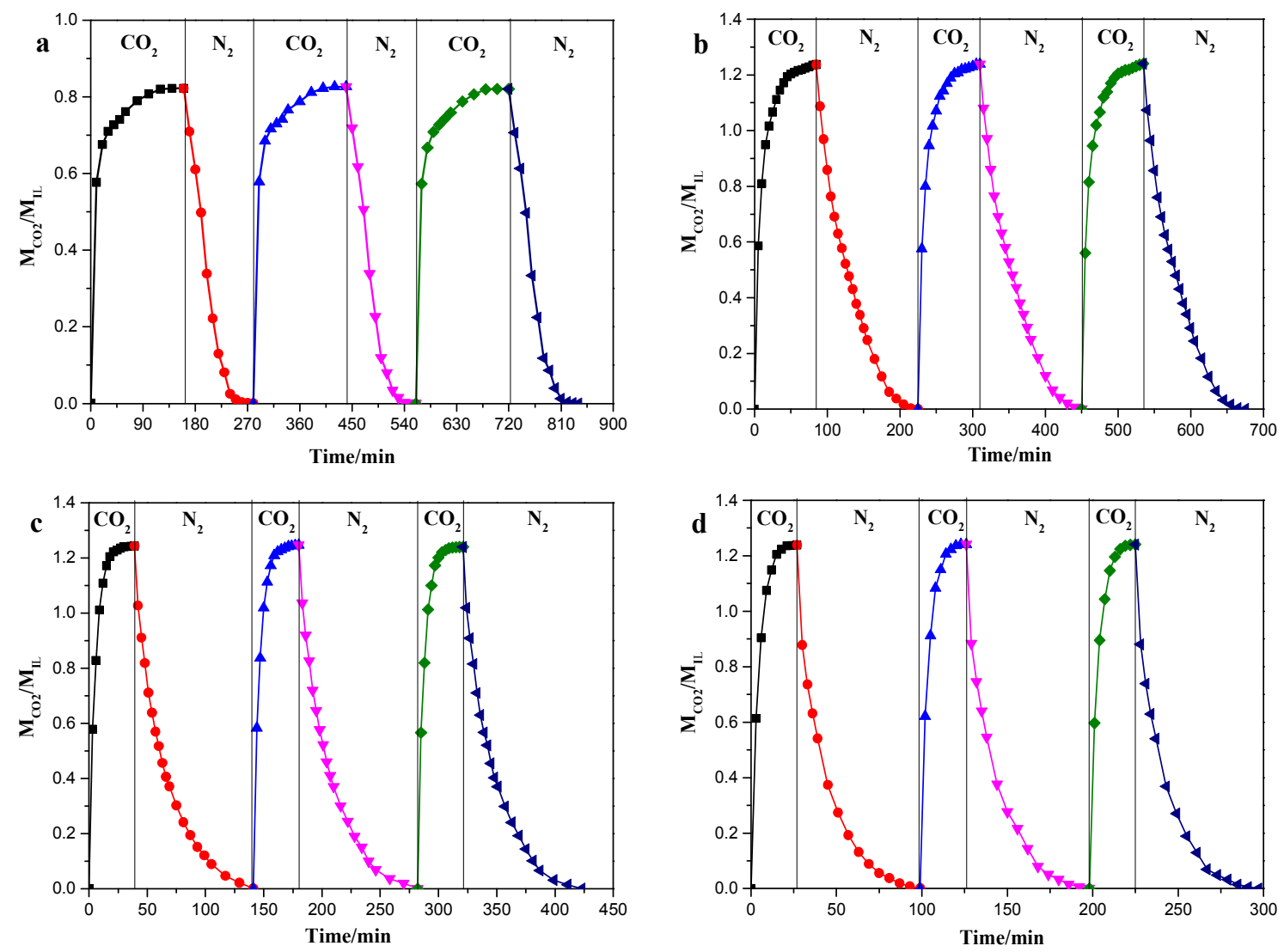

Fig. 3 Cycles of $\mathrm{CO}_{2}$ absorption and desorption by [TEPA]Ac and [TEPA]Ac/PEG-200

$$
\begin{aligned}
& \text { mixtures: a) } \left.\mathrm{W}_{[\mathrm{TEPA}] \mathrm{Ac}} / \mathrm{W}_{\text {PEG-200 }}=1: 0 \text { at } \mathrm{T}=383.15 \mathrm{~K} ; \mathrm{b}\right) \mathrm{W}_{[\mathrm{TEPA}] \mathrm{Ac}} / \mathrm{W}_{\text {PEG-200 }}=1: 1 \text { at } \\
& \left.\mathrm{T}=353.15 \mathrm{~K} ; \text { c) } \mathrm{W}_{\text {[TEPA }] A d} / \mathrm{W}_{\text {PEG-200 }}=1: 2 \text { at } \mathrm{T}=353.15 \mathrm{~K} ; \mathrm{d}\right) \mathrm{W}_{[\text {TEPA }] \text { Ac }} / \mathrm{W}_{\text {PEG-200 }}=1: 3 \text { at } \\
& \mathrm{T}=353.15 \mathrm{~K} \text {. }
\end{aligned}
$$

As shown in Figure 3, the capacities of [TEPA]Ac/PEG-200 mixtures are similar and the mole ratio of $\mathrm{CO}_{2}$ to [TEPA]Ac is about 1.24 at $353.15 \mathrm{~K}$, which is higher than other IL-based absorbents that reported by other authors even at a higher temperature (Table 1). Besides, the effect of PEG-200 content on the capacity of $\mathrm{CO}_{2}$ absorption by [TEPA]Ac was not significant, which indicates that the contribution of PEG-200 to the absorption of $\mathrm{CO}_{2}$ is very limited. The reason is that the $\mathrm{CO}_{2}$ could hardly be absorbed by PEG-200 at ambient pressure 
[29]. However, PEG-200 played the role as solvent for [TEPA]Ac and could increase the efficiency of $\mathrm{CO}_{2}$ absorption significantly. In the desorption process, the absorbed $\mathrm{CO}_{2}$ can be easily released by bubbling dried $\mathrm{N}_{2}$ through the solution. Besides, the results for ten cycles of $\mathrm{CO}_{2}$ absorption and desorption by [TEPA]Ac/PEG-200 mixture $\left(\mathrm{W}_{[\mathrm{TEPA}] \mathrm{Ad}} /{ }_{\mathrm{WPEG}-200}=1: 3\right)$ are shown in Fig. 4. It can be seen that no observed loss of absorption capacity was found during the ten cycles, indicating that the absorbent can be completely regenerated.

Table 1. Comparisons of $\mathrm{CO}_{2}$ capacity and viscosity of [TEPA]Ac/PEG-200 (mass ratio = 1:3) with IL-based absorbents around the ambient pressure.

\begin{tabular}{|c|c|c|c|c|c|}
\hline \multirow[t]{2}{*}{ Absorbents } & \multirow{2}{*}{$\begin{array}{l}\text { Tempera } \\
\text { ture, } \mathrm{K}\end{array}$} & \multirow{2}{*}{$\begin{array}{l}\mathrm{mol} \mathrm{CO}_{2} \\
/ \mathrm{mol} \mathrm{IL}\end{array}$} & \multicolumn{2}{|l|}{ Viscosity, $\mathrm{mPa} \cdot \mathrm{s}$} & \multirow[t]{2}{*}{ Ref. } \\
\hline & & & Before absorption & After absorption & \\
\hline [TEPA]Ac/PEG-200 $\left(\mathrm{M}^{\mathrm{a}}=\right.$ & 353.15 & $1.24^{\mathrm{b}}$ & 30 & 78 & This work \\
\hline \multicolumn{6}{|l|}{ 3) } \\
\hline [TEPA]Ac & 353.15 & 1.24 & 130 & 1550 & This work \\
\hline$\left[\mathrm{P}_{66614}\right][$ Ile $]$ & 353.15 & ---- & 97 & 1300 & {$[30]$} \\
\hline$\left[\mathrm{P}_{66614}\right][\mathrm{Gly}]$ & 353.15 & ---- & 95 & 650 & {$[30]$} \\
\hline$\left[\mathrm{P}_{66614}\right][\mathrm{Ile}]$ & 298.15 & $0.97^{\mathrm{c}}$ & 430 & 100000 & {$[30]$} \\
\hline$\left[\mathrm{P}_{66614}\right][$ Ala $]$ & 298.15 & $0.66^{\mathrm{c}}$ & 450 & 53000 & {$[30]$} \\
\hline$\left[\mathrm{P}_{66614}\right][\mathrm{Sar}]$ & 298.15 & $0.91^{\mathrm{c}}$ & 440 & 83000 & {$[30]$} \\
\hline$\left[\mathrm{P}_{66614}\right][\mathrm{o}-\mathrm{AA}]$ & 303.15 & 0.60 & ---- & ---- & {$[31]$} \\
\hline$\left[\mathrm{P}_{66614}\right][\mathrm{o}-\mathrm{AA}]$ & 343.15 & 0.16 & ---- & ---- & {$[31]$} \\
\hline$\left[\mathrm{P}_{66614}\right][\mathrm{p}-\mathrm{AA}]$ & 303.15 & 0.92 & ---- & ---- & [31] \\
\hline
\end{tabular}


$\left[\mathrm{P}_{66614}\right][\mathrm{p}-\mathrm{AA}] \quad 343.15 \quad 0.41$

$[\mathrm{DETA}] \cdot \mathrm{Cl} / \mathrm{EG}\left(\mathrm{R}^{\mathrm{d}}=4.0\right) \quad 303.15 \quad 0.90$

$[\mathrm{DETA}] \cdot \mathrm{Cl} / \mathrm{EG}\left(\mathrm{R}^{\mathrm{d}}=4.0\right) \quad 323.15 \quad 0.71$

[emim] $[2-\mathrm{CNPyr}]$

$295.15 \quad 0.80$

[emim][4-Triaz]

295.15

0.72

$---$

[emim] $[3-$ Triaz $]$

$295.15 \quad 0.53$

$----$

${ }^{\mathrm{a}} \mathrm{M}$ stands for mass ratio of PEG-200 to [TEPA]Ac.

${ }^{\mathrm{b}} \mathrm{mol} \mathrm{CO} 2 / \mathrm{mol}[\mathrm{TEPA}] \mathrm{Ac}$.

${ }^{\mathrm{c}}$ Solubility of $\mathrm{CO}_{2}$ was calculated by linear interpolation of the nearest experimental data points.

${ }^{\mathrm{d}} \mathrm{R}$ stands for mole ratio of EG to [DETA] $\mathrm{Cl}$.

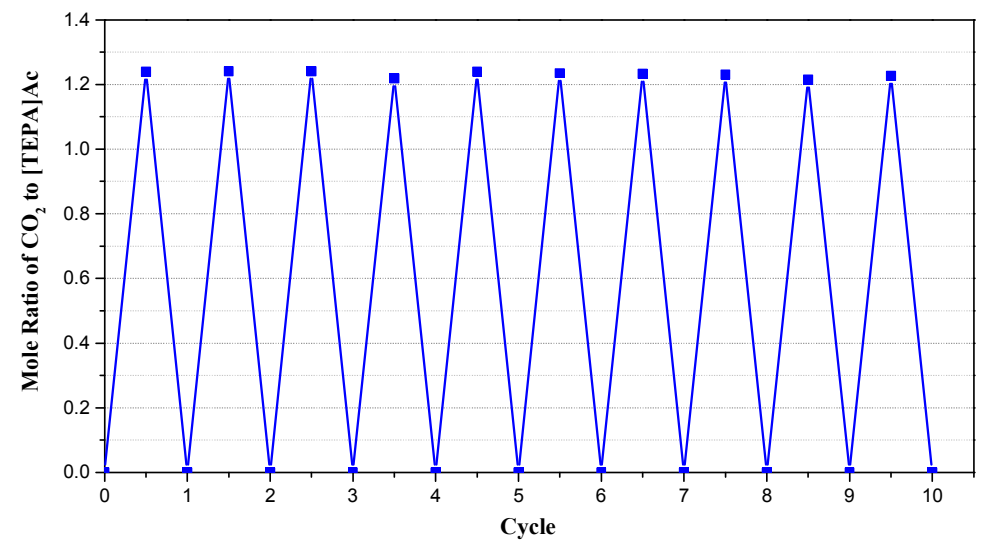

Fig. 4 Cycles of $\mathrm{CO}_{2}$ absorption and desorption by [TEPA]Ac/PEG-200 mixture

$$
\left(\mathrm{W}_{\text {[TEPA]Ad }} / \mathrm{W}_{\text {PEG-200 }}=1: 3\right)
$$

\subsection{Viscosity of the hybrid absorbent during the $\mathrm{CO}_{2}$ absorption}

Although [TEPA]Ac/PEG-200 has excellent properties, such as good circulation performance and high $\mathrm{CO}_{2}$ capacity at high temperatures, the viscosity of IL will increase 
with absorbing $\mathrm{CO}_{2}$ just as the other IL-based adsorbents $[4,30]$. For example, the viscosity of $\left[\mathrm{P}_{66614}\right][\mathrm{Ala}]$ increased from $450 \mathrm{mPa} \cdot \mathrm{s}$ to $53000 \mathrm{mPa} \cdot \mathrm{s}$ after saturated with $\mathrm{CO}_{2}$ (Table 1 ), which has a serious effect on the application of it for the capture of $\mathrm{CO}_{2}$. Viscosity of [TEPA]Ac/PEG-200 (mass ratio = 1:3) after the $\mathrm{CO}_{2}$ absorption at $353.15 \mathrm{~K}$ was measured, and the result is shown in Figure 5. The viscosity of [TEPA]Ac/PEG-200 mixture increased during the $\mathrm{CO}_{2}$ absorption. The reason for increasing viscosity of [TEPA]Ac/PEG-200 after absorbing $\mathrm{CO}_{2}$ is the formation of a hydrogen bond network during the $\mathrm{CO}_{2}$ absorption by [TEPA]Ac [34]. The viscosity of [TEPA]Ac/PEG-200 (mass ratio = 1:3) before and after the $\mathrm{CO}_{2}$ absorption was compared with other IL-based absorbents reported in the literatures (Table 1). It can be seen from Table 1, the viscosity of [TEPA]Ac/PEG-200 (mass ratio = 1:3) is just $78 \mathrm{mPa} \cdot \mathrm{s}$ after saturation with $\mathrm{CO}_{2}$, which is much lower than that of the other $\mathrm{CO}_{2}$-saturated IL-based adsorbents.

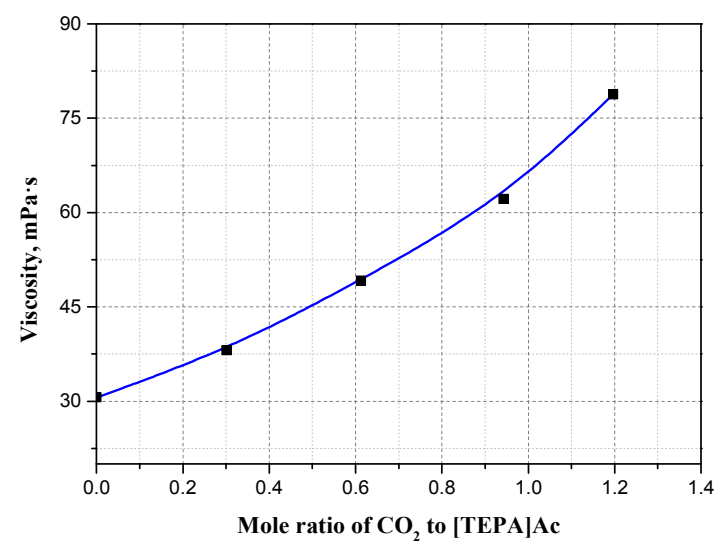

Fig. 5. Viscosity of [TEPA]Ac/PEG-200 (mass ratio = $1: 3$ ) during the absorption of $\mathrm{CO}_{2}$ at $353.15 \mathrm{~K}$ 
3.3 Solubility of $\mathrm{CO}_{2}$ in [TEPA]Ac/PEG-200 mixtures

The study of solubility of $\mathrm{CO}_{2}$ at equilibrium condition is very important and valuable for both fundamental research and practical applications of the [TEPA]Ac/PEG-200 mixtures. The results of the $\mathrm{CO}_{2}$ solubility in the [TEPA]Ac/PEG-200 mixtures with different mass ratio and at four temperatures $(353.15 \mathrm{~K}, 368.15 \mathrm{~K}, 383.15 \mathrm{~K}$, and $395.15 \mathrm{~K})$ were shown in Table 2. where $\mathrm{x}_{1}$ and $\mathrm{P}$ represents the mole fraction of $\mathrm{CO}_{2}$ in the absorbent and the equilibrium pressure, respectively.

Table 2 Mole ratio of $\mathrm{CO}_{2}$ to [TEPA]Ac $\left(\mathrm{M}_{\mathrm{CO}_{2}} / \mathrm{M}_{[\mathrm{TEPA}] \mathrm{Ac}}\right)$ at different temperatures and pressures.

\begin{tabular}{|c|c|c|c|c|c|c|c|c|c|}
\hline \multirow{3}{*}{$\mathrm{T} / \mathrm{K}$} & \multicolumn{3}{|c|}{$\mathrm{W}_{\mathrm{IL}} / \mathrm{W}_{\mathrm{PEG}-200}=1: 1$} & \multicolumn{3}{|c|}{$\mathrm{W}_{\mathrm{IL}} / \mathrm{W}_{\mathrm{PEG}-200}=1: 2$} & \multicolumn{3}{|c|}{$\mathrm{W}_{\mathrm{IL}} / \mathrm{W}_{\mathrm{PEG}-200}=1: 3$} \\
\hline & $\mathrm{P} / \mathrm{bar}$ & $\mathrm{x}_{1}{ }^{*}$ & $\mathrm{M}_{\mathrm{CO}_{2}} / \mathrm{M}_{\mathrm{I}}$ & $\mathrm{P} /$ bar & $\mathrm{x}_{1}{ }^{*}$ & $\mathrm{M}_{\mathrm{CO}_{2}} / \mathrm{M}_{\mathrm{C}}$ & $\mathrm{P} /$ bar & $\mathrm{x}_{1}{ }^{*}$ & $\mathrm{M}_{\mathrm{CO}_{2}} / \mathrm{M}_{[}$ \\
\hline & & & TEPA]Ac & & & TEPA]Ac & & & TEPA]Ac \\
\hline \multirow[t]{6}{*}{353.15} & 0.0455 & 0.0373 & 0.0838 & 0.0195 & 0.0168 & 0.0585 & 0.0050 & 0.0087 & 0.0380 \\
\hline & 0.2205 & 0.2889 & 0.6485 & 0.2095 & 0.1844 & 0.6435 & 0.1795 & 0.1352 & 0.5917 \\
\hline & 0.4005 & 0.4251 & 0.9544 & 0.4185 & 0.2703 & 0.9435 & 0.4585 & 0.2266 & 0.9912 \\
\hline & 0.6055 & 0.4878 & 1.0951 & 0.6055 & 0.3102 & 1.0825 & 0.6340 & 0.2512 & 1.0990 \\
\hline & 0.8080 & 0.5350 & 1.2010 & 0.7505 & 0.3339 & 1.1652 & 0.8420 & 0.2754 & 1.2050 \\
\hline & 1.0000 & 0.5523 & 1.2400 & 0.9560 & 0.3542 & 1.2361 & 0.9965 & 0.2846 & 1.2450 \\
\hline \multirow[t]{3}{*}{368.15} & 0.0585 & 0.0554 & 0.1243 & 0.0185 & 0.0196 & 0.0684 & 0.0185 & 0.0188 & 0.0821 \\
\hline & 0.2850 & 0.2198 & 0.4935 & 0.3050 & 0.1487 & 0.5191 & 0.2470 & 0.1011 & 0.4421 \\
\hline & 0.4285 & 0.3286 & 0.7376 & 0.4225 & 0.2077 & 0.7249 & 0.4620 & 0.1745 & 0.7634 \\
\hline
\end{tabular}




\begin{tabular}{|c|c|c|c|c|c|c|c|c|c|}
\hline & 0.6165 & 0.3909 & 0.8775 & 0.5865 & 0.2444 & 0.8529 & 0.6320 & 0.1998 & 0.8741 \\
\hline & 0.8055 & 0.4313 & 0.9682 & 0.7955 & 0.2744 & 0.9576 & 0.7855 & 0.2151 & 0.9411 \\
\hline & 0.9890 & 0.4606 & 1.0341 & 0.9690 & 0.2926 & 1.0212 & 0.9950 & 0.2360 & 1.0326 \\
\hline \multirow[t]{6}{*}{383.15} & 0.1145 & 0.0524 & 0.1177 & 0.1025 & 0.0321 & 0.1121 & 0.1365 & 0.0360 & 0.1574 \\
\hline & 0.2635 & 0.1328 & 0.2981 & 0.2155 & 0.0761 & 0.2655 & 0.3100 & 0.0841 & 0.3680 \\
\hline & 0.4490 & 0.2355 & 0.5288 & 0.4230 & 0.1461 & 0.5099 & 0.4630 & 0.1262 & 0.5520 \\
\hline & 0.6265 & 0.3087 & 0.6931 & 0.6755 & 0.2036 & 0.7106 & 0.6230 & 0.1579 & 0.6910 \\
\hline & 0.8230 & 0.3491 & 0.7837 & 0.8145 & 0.2231 & 0.7758 & 0.7990 & 0.1770 & 0.7743 \\
\hline & 0.9955 & 0.3648 & 0.8190 & 0.9990 & 0.2350 & 0.8200 & 0.9840 & 0.1867 & 0.8170 \\
\hline \multirow[t]{6}{*}{398.15} & 0.0385 & 0.0011 & 0.0025 & 0.0365 & 0.0006 & 0.0021 & 0.0250 & 0.0004 & 0.0018 \\
\hline & 0.2315 & 0.0815 & 0.1830 & 0.2625 & 0.0559 & 0.1952 & 0.2215 & 0.0395 & 0.1730 \\
\hline & 0.4360 & 0.1524 & 0.3421 & 0.4625 & 0.1035 & 0.3621 & 0.3950 & 0.0755 & 0.3302 \\
\hline & 0.6170 & 0.1885 & 0.4231 & 0.5830 & 0.1182 & 0.4125 & 0.6040 & 0.0956 & 0.4181 \\
\hline & 0.8040 & 0.2264 & 0.5082 & 0.7990 & 0.1447 & 0.5049 & 0.8105 & 0.1166 & 0.5100 \\
\hline & 0.9895 & 0.2453 & 0.5506 & 0.9955 & 0.1581 & 0.5518 & 0.9845 & 0.1260 & 0.5512 \\
\hline
\end{tabular}

\footnotetext{
* $\mathrm{x}_{1}$, mole ratio of $\mathrm{CO}_{2}$ to [TEPA]Ac/PEG-200 mixture
}

Figure 6 illustrates the isothermal solubility behavior of the [TEPA]Ac/PEG-200 mixtures at different temperatures. The solubility of $\mathrm{CO}_{2}$ in the [TEPA]Ac/PEG-200 mixtures increased significantly with the increase of pressure. The $\mathrm{CO}_{2}$ solubility is more sensitive to pressure in the low-pressure range. Also, it was shown that at each pressure, the solubility of $\mathrm{CO}_{2}$ in the [TEPA]Ac/PEG-200 mixtures decreased with the increasing of temperature (Fig. 
$6)$.
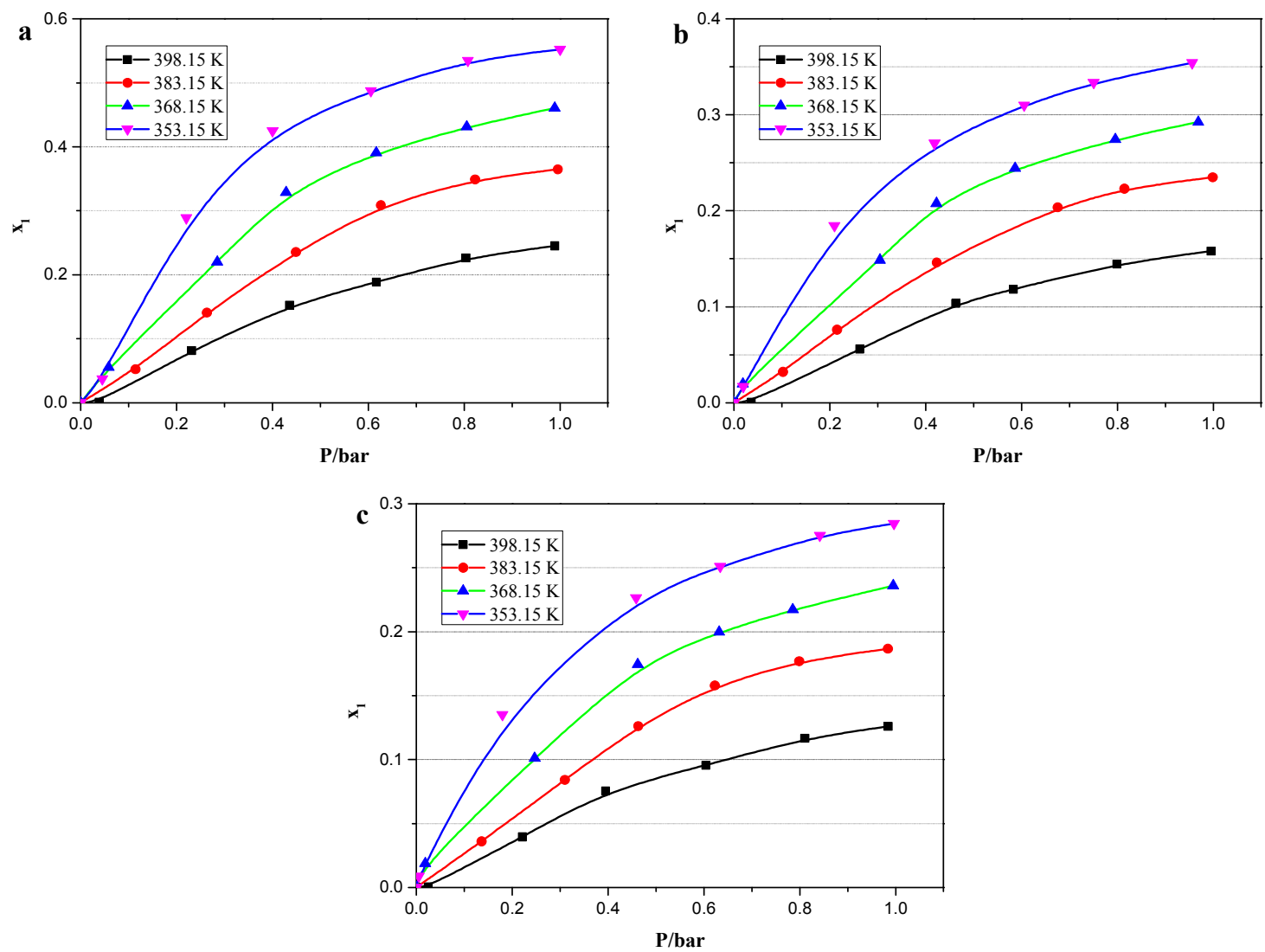

Fig. 6 Dependence of the solubility of $\mathrm{CO}_{2}$ in the [TEPA]Ac/PEG-200 mixtures on temperature and pressure: a) $\mathrm{W}_{[\mathrm{TEPA}] \mathrm{Ac}} / \mathrm{W}_{\mathrm{PEG}-200}=1: 1 ;$ b) $\left.\mathrm{W}_{[\mathrm{TEPA}] \mathrm{Ac}} / \mathrm{W}_{\mathrm{PEG}-200}=1: 2 ; \mathrm{c}\right)$ $\mathrm{W}_{\text {[TEPA]Ac }} / \mathrm{W}_{\text {PEG-200 }}=1: 3\left(\mathrm{x}_{1}\right.$, mole ratio of $\mathrm{CO}_{2}$ to $[\mathrm{TEPA}] \mathrm{Ac} / \mathrm{PEG}-200$ mixture $)$

At the same temperature and pressure, the solubility of $\mathrm{CO}_{2}$ in the [TEPA]Ac/PEG-200 mixtures decreased with the increase of the PEG-200 content. The reason is that the PEG-200 could hardly absorb $\mathrm{CO}_{2}$ at each temperature and pressure which has been discussed above. Distribution of the molar ratio of $\mathrm{CO}_{2}$ to [TEPA]Ac $\left(\mathrm{M}_{\mathrm{CO}_{2}} / \mathrm{M}_{[\mathrm{TEPA}] \mathrm{Ac}}\right)$ in the experiment at different [TEPA]Ac to PEG-200 mass ratios was shown in Figure 7 in order to describe 
clearly the role of [TEPA]Ac and PEG-200 for the $\mathrm{CO}_{2}$ absorption. The effect of the mass ratio of [TEPA]Ac to PEG-200 on the $\mathrm{M}_{\mathrm{CO}_{2}} / \mathrm{M}_{[\mathrm{TEPA}] \mathrm{Ac}}$ is very limited. Almost all amount of $\mathrm{CO}_{2}$ was absorbed by [TEPA]Ac due to the strong interaction between the basic group of [TEPA]Ac and $\mathrm{CO}_{2}$.
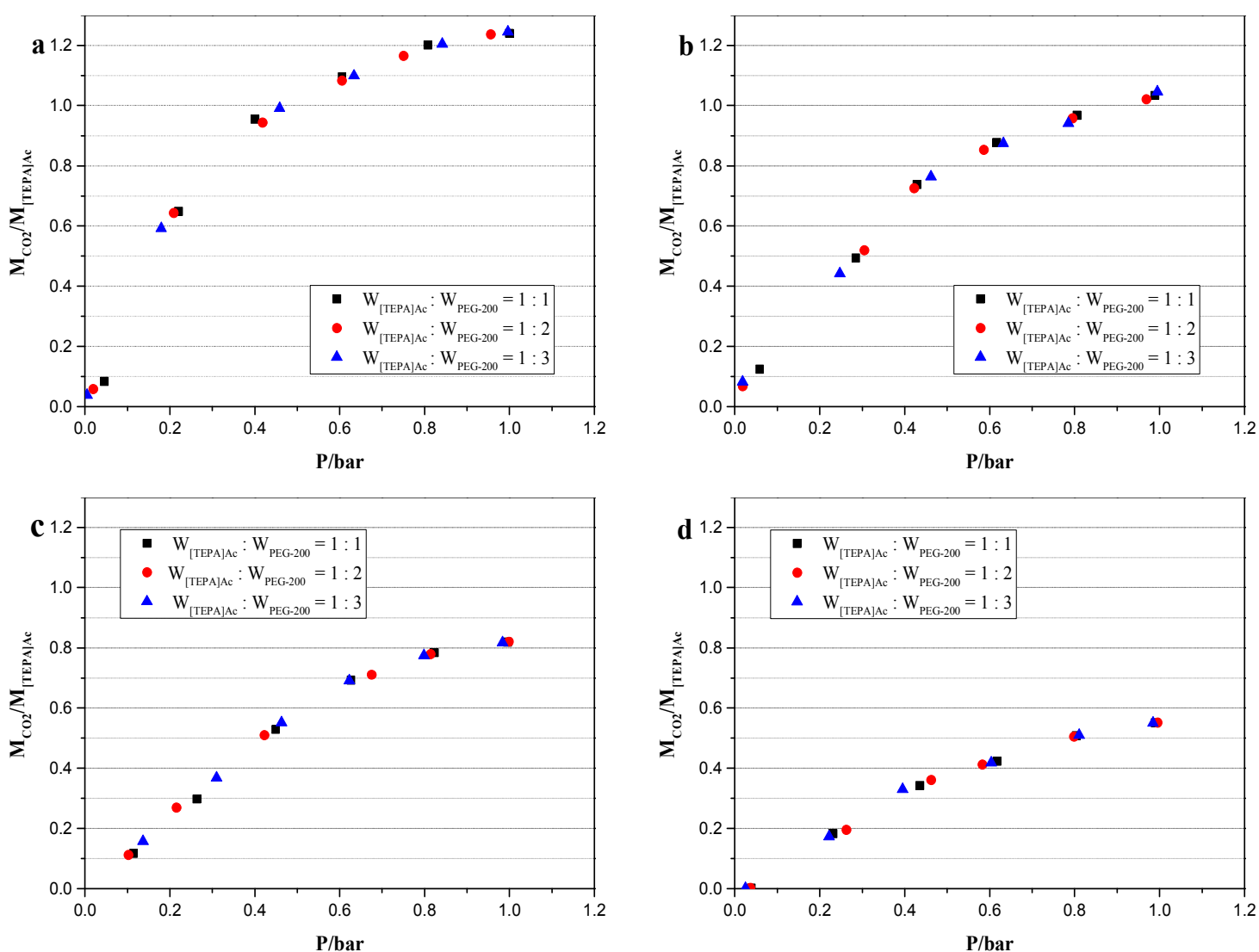

Fig. 7 The effect of temperature and pressure on the molar ratio of $\mathrm{CO}_{2}$ to $[\mathrm{TEPA}] \mathrm{Ac}\left(\mathrm{M}_{\mathrm{CO}_{2}} /\right.$ $\mathrm{M}_{\text {[TEPA]Ac): }}$ a): $\mathrm{T}=353.15 \mathrm{~K}$; b) $\mathrm{T}=368.15 \mathrm{~K}$; c) $\mathrm{T}=383.15 \mathrm{~K}$; d) $\mathrm{T}=398.15 \mathrm{~K}$.

\subsection{Enthalpy and entropy of solution}

The strength of interaction between $\mathrm{CO}_{2}$ and absorbent can be reflected by enthalpy $\left(\Delta \mathrm{H}_{\mathrm{sol}}\right)$, and the order degree changing of solution during the capture of $\mathrm{CO}_{2}$ can be reflected 
by entropy $\left(\Delta \mathrm{S}_{\mathrm{sol}}\right)$, i.e. the $\Delta \mathrm{H}_{\mathrm{sol}}$ and $\Delta \mathrm{S}_{\mathrm{sol}}$ are important thermodynamic parameters for the investigated system. $\Delta \mathrm{H}_{\mathrm{sol}}$ and $\Delta \mathrm{S}_{\mathrm{sol}}$ can be calculated through the following equations [35]:

$$
\begin{aligned}
\frac{\Delta \mathrm{H}_{\mathrm{Sol}}}{R} & =\left(\frac{\partial \ln \mathrm{P}}{\partial(1 / \mathrm{T})}\right) \mathrm{x}_{1} \\
\frac{\Delta \mathrm{S}_{\mathrm{Sol}}}{R} & =-\left(\frac{\partial \ln \mathrm{P}}{\partial \mathrm{T}}\right) \mathrm{x}_{1}
\end{aligned}
$$

where $\mathrm{x}_{1}$ is the mole fraction of $\mathrm{CO}_{2}$ in the [TEPA]Ac/PEG-200 mixtures, $\mathrm{R}$ is the molar gas constant. In the system investigated in this work, $\ln \mathrm{P}$ had a linear relationship with $1 / \mathrm{T}$ and $\ln \mathrm{T}$ at fixed $\mathrm{x}_{1}$. For example, the dependence of $\ln \mathrm{P}_{1}$ on $1 / \mathrm{T}$ at $\mathrm{x}_{1}=0.055$ and $\mathrm{W}_{\mathrm{IL}} / \mathrm{W}_{\mathrm{PEG}-200}=$ $1: 1$ was shown in Figure 8. The values of $\Delta \mathrm{H}_{\text {sol }}$ and $\Delta \mathrm{S}_{\text {sol }}$ at four fixed values of $\mathrm{x}_{1}$ for each [TEPA]Ac/PEG-200 mixture were calculated and listed in Table 3.
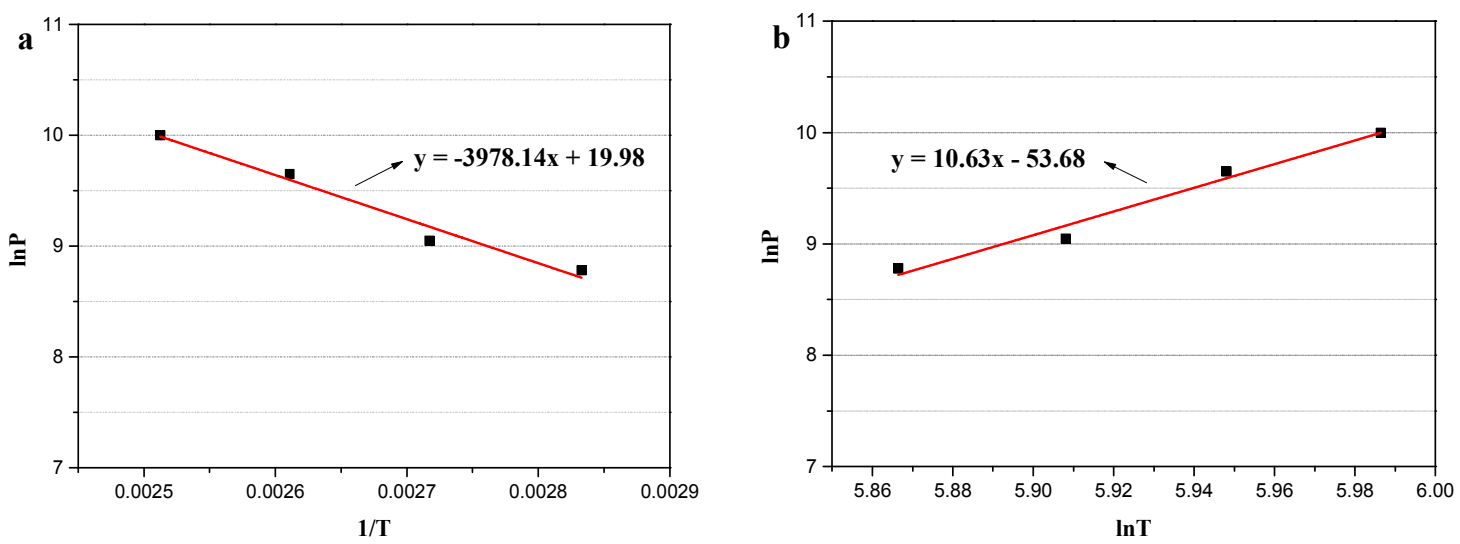

Fig. 8 Relationship between $\ln \mathrm{P}$ and $1 / \mathrm{T}$ or $\ln \mathrm{T}$ at $\mathrm{x}_{1}=0.055$ for the [TEPA]Ac/PEG-200 mixture with the mass ratio of $1: 1$

Table 3 Enthalpy $(\mathrm{kJ} / \mathrm{mol})$ and entropy $\left(\mathrm{J} / \mathrm{K} \mathrm{mol}^{-1}\right)$ of solution of $\mathrm{CO}_{2}$ in the [TEPA]Ac/PEG-200 mixtures $(\mathrm{T}=353.15-395.15 \mathrm{~K})$

$$
\mathrm{W}_{\text {[TEPA]Ac }} / \mathrm{W}_{\text {PEG-200 }}=1: 1 \quad \mathrm{~W}_{\text {[TEPA]Ac }} / \mathrm{W}_{\text {PEG-200 }}=1: 2 \quad \mathrm{~W}_{\text {[TEPA]Ac }} / \mathrm{W}_{\text {PEG-200 }}=1: 3
$$




\begin{tabular}{|c|c|c|c|c|c|c|c|c|}
\hline $\mathrm{x}_{1}{ }^{*}$ & $-\Delta \mathrm{H}_{\mathrm{sol}}$ & $-\Delta \mathrm{S}_{\mathrm{sol}}$ & $\mathrm{x}_{1}{ }^{*}$ & $-\Delta \mathrm{H}_{\mathrm{sol}}$ & $-\Delta \mathrm{S}_{\mathrm{sol}}$ & $\mathrm{x}_{1}{ }^{*}$ & $-\Delta \mathrm{H}_{\mathrm{sol}}$ & $-\Delta \mathrm{S}_{\mathrm{sol}}$ \\
\hline 0.055 & 33.1 & 88.4 & 0.045 & 35.8 & 95.7 & 0.030 & 36.6 & 97.6 \\
\hline 0.115 & 33.5 & 89.6 & 0.085 & 35.8 & 95.5 & 0.065 & 36.9 & 98.4 \\
\hline 0.175 & 35.6 & 95.1 & 0.120 & 37.7 & 100.6 & 0.095 & 38.1 & 101.6 \\
\hline 0.235 & 42.3 & 113.2 & 0.155 & 41.5 & 111.1 & 0.125 & 40.0 & 107.1 \\
\hline
\end{tabular}

$* \mathrm{x}_{1}$, mole fraction of $\mathrm{CO}_{2}$ in the [TEPA]Ac/PEG-200 mixtures

Under all conditions, the $\Delta \mathrm{H}_{\text {sol }}$ of absorbents has negative values indicating that a large amount of heat is released during the absorption process. This feature should be taken into consideration during the process of practical application. Also, the large negative values of $\Delta \mathrm{H}_{\text {sol }}$ indicate that the interaction between the [TEPA]Ac/PEG-200 mixtures and $\mathrm{CO}_{2}$ is quite strong. The $\Delta \mathrm{S}_{\mathrm{sol}}$ can reflect structure change of the absorbent before and after the $\mathrm{CO}_{2}$ absorption. Thus, the negative values of $\Delta \mathrm{S}_{\mathrm{sol}}$ demonstrate that the structure of the [TEPA]Ac/PEG-200 mixtures has higher ordering degree after the absorption of $\mathrm{CO}_{2}$.

\section{Conclusions}

The [TEPA]Ac/PEG-200 mixture is a new type of IL-based absorbent for $\mathrm{CO}_{2}$ capture. It has excellent properties, such as good circulation performance and high $\mathrm{CO}_{2}$ capacity at high temperatures. The main conclusions can be summarized as follow:

The [TEPA]Ac/PEG-200 mixtures have high $\mathrm{CO}_{2}$ absorption capacity and the mole ratio of $\mathrm{CO}_{2}$ to [TEPA]Ac can reach 1.24 at $353.15 \mathrm{~K}$ under the ambient pressure $(1.01$ bar). Moreover, the absorbents can absorb $\mathrm{CO}_{2}$ effectively at a higher temperature indicating that 
they have potential application to capture $\mathrm{CO}_{2}$ from flue gas in the industry.

The [TEPA]Ac/PEG-200 mixtures with $\mathrm{CO}_{2}$ absorbed can be easily regenerated by bubbling $\mathrm{N}_{2}$ through the absorbents. No observed loss of absorption capacity was found during ten absorption and desorption circulations, indicating that the absorbent can be completely regenerated.

The addition of PEG-200 increased significantly the $\mathrm{CO}_{2}$ absorption efficiency of the absorbent.

The solubility of $\mathrm{CO}_{2}$ in the [TEPA]Ac/PEG-200 mixtures decreased with increasing temperature or decreasing $\mathrm{CO}_{2}$ partial pressure.

The $\mathrm{CO}_{2}$ absorption in the [TEPA]Ac/PEG-200 mixtures is an exothermic process and the ordering degree of the absorbent structure increases during the $\mathrm{CO}_{2}$ absorption.

\section{Acknowledgements}

This work was supported by the National Natural Science Foundation of China (NSFC, No. 5141101056).

\section{References}

[1] N. MacDowell, N. Florin, A. Buchard, J. Hallett, A. Galindo, G. Jackson, C. S. Adjinman, C. K. Williams, N. Shah and P. Fennell, An overview of $\mathrm{CO}_{2}$ capture technologies, Energy Environ. Sci. 3 (2010) $1645-1669$.

[2] G.T. Rochelle, Amine scrubbing for $\mathrm{CO}_{2}$ capture, Science. 325 (2009) 1652-1654.

[3] D. M. D. Alessandro, B. Smit, J. R. Long, Carbon dioxide capture: prospects for new materials, Angew. 
Chem. Int. Ed. 49 (2010) 6058-6082.

[4] F. Karadas, M. Atilhan, S. Aparicio, Review on the use of ionic liquids (ILs) as alternative fluids for $\mathrm{CO}_{2}$ capture and natural gas sweetening, Energy \& Fuels 24 (2010) 5817-5828.

[5] Jie Shen, Gongping Liu, Kang Huang, Membranes with Fast and Selective Gas-Transport Channels of Laminar Graphene Oxide for Efficient $\mathrm{CO}_{2}$ Capture, Angew. Chem. 127 (2015) 588-592.

[6] G.T. Rochelle, 3-Conventional amine scrubbing for $\mathrm{CO}_{2}$ capture, Absorption-Based Post-combustion Capture of Carbon Dioxide, 2016 35-67.

[7] R. Idem, P. Tontiwachwuthikul, Preface for the special issue on the capture of carbon dioxide from industrial sources: Technological developments and future opportunities, Ind. Eng. Chem. Res. 45 (2006) 2413.

[8] Davison J, Thambimuthu K, An overview of technologies and costs of carbon dioxide capture in power generation. Proc. Inst. Mech. Eng. Part A 223 (2009) 201-212.

[9] M.L. Gray, Y. Soong, K.J. Champagne, H. Pennline, J.P. Baltrus, R.W. Stevens Jr., R. Khatri, S.S.C. Chuang, T. Filburn, Improved immobilized carbon dioxide capture sorbents, Fuel Process. Technol. 86 (2005) 1449-1455.

[10] K.A. Hoff, O. Juliussen, O. Falk-Pedersen, H. F. Svendsen, Modeling and experimental study of carbon dioxide absorption in aqueous alkanolamine solutions using a membrane contactor, Ind. Eng. Chem. Res. 43 (2004) 4908-4921.

[11] MacDowell N, Florin N, Buchard A, Hallett J, Galindo A, Jackson G, An overview of $\mathrm{CO}_{2}$ capture technologies. Energy Environ Sci. 3 (2010) 1645-1649.

[12] Bara JE, Camper DE, Gin DL, Noble RD, Room-temperature ionic liquids and composite materials: platform technologies for $\mathrm{CO}_{2}$ capture. Acc. Chem. Res. 43 (2010) 152-159. 
[13] Blanchard, L.A., Hancu, D., Beckman, E.J., Brennecke, J.F., Green processing using ionic liquids and $\mathrm{CO}_{2}$, Nature 399 (1999) 28-29.

[14] I. Iliuta, M. Hasib-ur-Rahman, F. Larachi, $\mathrm{CO}_{2}$ absorption in diethanolamine/ionic liquid emulsionsChemical kinetics and mass transfer study, Chem. Eng. J. 240 (2014) 16-23.

[15] Akihito Otani, Yong Zhang, Tatsuya Matsuki, Eiji Kamio, Hideto Matsuyama, Edward J. Maginn, Molecular Design of $\mathrm{High} \mathrm{CO}_{2}$ Reactivity and Low Viscosity Ionic Liquids for $\mathrm{CO}_{2}$ Separative Facilitated Transport Membranes, Ind. Eng. Chem. Res. 55 (2016) 2821-2830.

[16] E.D. Bates, R.D. Mayton, I. Ntai, J.H. Davis, $\mathrm{CO}_{2}$ capture by a task-specific ionic liquid, J. AM. Chem. Soc. 124 (2002) 926-927.

[17] L. M. Galan Sanchez, G. W. Meindersma and A. B. de Haan, Solvent Properties of Functional Ionic Liquids for $\mathrm{CO}_{2}$ absorption, Chem. Eng. Res. Des. 85 (2007) 31-39.

[18] Gurkan B.E., de la Fuente J.C., Mindrup E.M., Ficke L.E. Equimolar $\mathrm{CO}_{2}$ Absorption by Anion-Functionalized Ionic Liquids, J. Am. Chem. Soc. 132 (2010) 2116-2117.

[19] J. M. Zhang, S. J. Zhang, K. Dong, Y. Q. Zhang, Y. Q. Shen and X. M. Lv, Supported absorption of $\mathrm{CO}_{2}$ by tetrabutylphosphonium amino acid ionic liquids, Chem. Eur. J. 12 (2006) 4021-4026.

[20] Haibo Xie, Suobo Zhang, Shenghai Li, Chitin and chitosan dissolved in ionic liquids as reversible sorbents of $\mathrm{CO}_{2}$, Green Chem. 8 (2006) 630-633.

[21] M.D. Bermejo, T.M. Fieback, A. Martín, Solubility of gases in 1-alkyl-3methylimidazolium alkyl sulfate ionic liquids: experimental determination and modeling, J. Chem. Thermodynamics 58 (2013) 237244.

[22] M. E. Boot-Handford, J. C. Abanades, E. J. Anthony, M. J. Blunt, S. Brandani, Carbon capture and storage update, Energy Environ. Sci. 7 (2014) 130-189. 
[23] Q Huang, Y Li, XB Jin, D Zhao, G.Z. Chen, Chloride ion enhanced thermal stability of carbon dioxide captured by monoethanolamine in hydroxyl imidazolium based ionic liquids, Energy Environ. Sci. 4 (2011) $2125-2133$.

[24] J.E. Bara, T.K. Carlisle, C.J. Gabriel, D. Camper, A. Finotello, D.L. Gin, R.D. Noble, Guide to $\mathrm{CO}_{2}$ separations in imidazolium-based room-temperature ionic liquids, Ind. Eng. Chem. Res. 48 (2009) 27392751.

[25] J. Chen, S. K. Spear, J. G. Huddleston and R. D. Rogers, Polyethylene glycol and solutions of polyethylene glycol as green reaction media, Green Chem. 7 (2005) 64-82.

[26] Xia Gui., Zhigang Tang, Weiyang Fei, Solubility of $\mathrm{CO}_{2}$ in alcohols, glycols, ethers, and ketones at high pressures from (288.15 to 318.15) K, J. Chem. Eng. 56 (2011), 2420-2429.

[27] Xiaofeng Li, Dongshun Deng, Investigation of the weak basic butyltriethylammonium acetylacetonate and polyethylene glycol mixture as a new efficient $\mathrm{CO}_{2}$ absorption solvent, J. Chem. Thermodynamics. 79 (2014) 230-234.

[28] CM Wang, XY Luo, X Zhu, GK Cui, De-en Jiang, DS Deng, HR Li, S Dai, The strategies for improving carbon dioxide chemisorption by functionalized ionic liquids, RSC Adv. 3 (2013) 15518-15527.

[29] Jun Li, Yinmei Ye, Lifting Chen, Zhiwen Qi. Solubilities of $\mathrm{CO}_{2}$ in poly (ethylene glycols) from (303.15 to 333.15) K. J. Chem. Eng. Data 57 (2012) 610-612.

[30] Goodrich BF, Fuente JC, Gurkan BE, Zadigian DJ, Price EA, Huang Y, Experimental measurements of amine-functionalized anion-tethered ionic liquids with carbon dioxide, Ind. Eng. Chem. Res. 50 (2011) $111-118$.

[31] Xiao Y. Luo, Fang Ding, Wen J. Lin, Yu Q. Qi, Hao R. Li, and Cong M. Wang, Efficient and Energy-Saving $\mathrm{CO}_{2}$ Capture through the Entropic Effect Induced by the Intermolecular Hydrogen Bonding 
in Anion-Functionalized Ionic Liquids, J. Phys. Chem. 5 (2014) 381-386.

[32] Shidong Tian, Yucui Hou, Weize Wu, Shuhang Ren, Jianguo Qian, Reversible absorption of $\mathrm{CO}_{2}$ by diethylenetriamine hydrochloride and ethylene glycol mixtures with high capacity and low viscosity, Journal of the Taiwan Institute of Chemical Engineers 49 (2015) 95-99.

[33] Samuel Seo, M. Aruni DeSilva, and Joan F. Brennecke, Physical Properties and $\mathrm{CO}_{2}$ Reaction Pathway of 1 Ethyl-3- Methylimidazolium Ionic Liquids with Aprotic Heterocyclic Anions, J. Phys. Chem. 118 (2014) 14870-14879.

[34] Gutowski KE, Maginn EJ. Amine-functionalized task-specific ionic liquids: a mechanistic explanation for the dramatic increase in viscosity upon complexation with $\mathrm{CO}_{2}$ from molecular simulation, $\mathrm{J}$ Am Chem. Soc. 130 (2008) 14690-14704.

[35] J.L. Anthony, E.J. Maginn, J.F. Brennecke, Solubilities and thermodynamic properties of gases in the ionic liquid 1-n-Butyl-3-methylimidazolium hexafluorophosphate, J. Phys. Chem. B. 106 (2002) 73157320. 